\title{
Index of Authors for Volume 11
}

Annison, E. F.

Bedford, M. R.

Blundell, J.

Brand-Miller, J. C.

Brooks, J. L.

Bryden, W. L.

Cheney, C. D.

Davies, G. J.

Day, J. E. L.

Dickerson, J. W. T.

Ferguson, E. L.

Forsyth, J. S.

Gibson, R. S.

Gordon, G. L. R.

Gurr, M. I.

Havenaar, R.

Holt, S. H. A.
$173 \quad$ Kyriazakis, I.

25,223

91 Macdiarmid, J.

231

231 Minekus, M.

45

279

173

Par̆izková, J.

71

133

199 Provenza, F. D.

199

279 Rogers, P. J.

25

25,223

279 Schulze, H.

91

Scott, J. M.

115 Shaw, A. D.

311

279

Smeets-Peeters, M.

45

115

133

1,169

Villalba, J. J.

199

Watson, $\mathrm{T}$.

45 Weir, D. G.

5 Werner, S. J. 